WellBeing International

WBI Studies Repository

4-1998

\title{
A Comparison of Encephalization between Odontocete Cetaceans and Anthropoid Primates
}

L. Marino

Emory University

Follow this and additional works at: https://www.wellbeingintlstudiesrepository.org/acwp_vsm

Part of the Animal Studies Commons, Other Animal Sciences Commons, and the Other Ecology and Evolutionary Biology Commons

\section{Recommended Citation}

Marino, L. (1998). A comparison of encephalization between odontocete cetaceans and anthropoid primates. Brain, Behavior and Evolution.

This material is brought to you for free and open access by WellBeing International. It has been accepted for inclusion by an authorized administrator of the WBI Studies Repository. For more information, please contact wbisr-info@wellbeingintl.org.

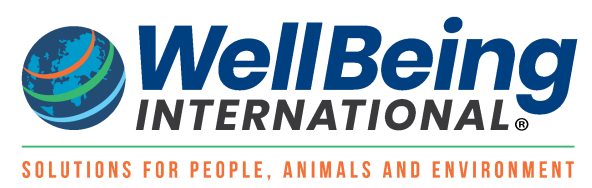




\title{
A Comparison of Encephalization between Odontocete Cetaceans and Anthropoid Primates
}

Lori Marino

Emory University

\author{
KEYWORDS \\ encephalization, brain size, brain evolution, cetaceans, odontocetes, primates
}

\begin{abstract}
There have been very few studies of brain size and encephalization in cetaceans and essentially none that have made direct quantitative comparisons of cetaceans and another mammalian group using large normative samples. In the present study two different measures of encephalization were calculated and used to rank and compare 21 odontocete species and 60 anthropoid primate species. Comparisons were made both within and between the two groups. Results show that the encephalization level of Homo sapiens is still extraordinary relative to that of nonhuman species. Nevertheless, a subset of delphinid odontocetes are significantly more highly encephalized than the most highly encephalized anthropoid primates and narrow the gap in encephalization between humans and nonhumans substantially. These findings may have implications for comparative models of the relative importance of brain size versus brain organization for the evolution of intelligence.
\end{abstract}

\section{Introduction}

The concept of encephalization, originally put forth in the form of an Encephalization Quotient (EQ) by Jerison [1955, 1963, 1973], has been widely applied to comparisons across different groups at many taxonomic levels. The EQ is a measure of relative brain size which, by incorporating the exponent and coefficient from the regression equation of log brain weight on log body weight, allows for the comparison of brain size across the range of body sizes within the sample. The EQ, therefore, is used as a measure of observed brain size relative to expected brain size, where expected brain size is determined by the value of the regression line that corresponds to the same body size. Values of one, less than one, and greater than one for EQ indicate that the group of interest (e.g., species) has a relative brain size that is average for its body weight, below the value expected on the basis of body weight, and above the value expected for its body weight, respectively. The logical implication of this kind of analysis is that EQ varies with the reference group [Harvey and Krebs, 1990].

Empirical studies of the relation between brain weight and body weight among a variety of mammalian species have generally converged on two power functions, 0.67 and 0.75 , for the relationship between brain and body weight. The two-thirds exponent was not originally empirically derived by Jerison [1973] but was, instead, chosen on the basis of the theoretical argument that brain size scales to body surface. The theoretical explanation for the three-fourths exponent has centered around arguments that brain size scales to basal metabolic rate [Eisenberg and Wilson, 1978; Martin, 1981; Hofman, 1983; Armstrong, 
1982, 1983, 1985]. Both power functions have been widely applied in the literature, and analyses have shown that most actual exponent values derived from brain weight-body weight regressions do not differ significantly from these values, particularly at taxonomic levels above that of genus [Pagel and Harvey, 1989].

There is a large body of data from numerous studies in which EQ (and related brain size indices) in primates and other terrestrial mammals was examined [Bauchot and Stephan, 1969; Passingham, 1975; Eisenberg and Wilson, 1978, 1981; Holloway, 1980; Mace et al., 1980; Bronson, 1981; Martin, 1981; Stephan et al., 1981; Hofman, 1982; Armstrong, 1982, 1983, 1985; McNab and Eisenberg, 1989]. Nevertheless, there have been few studies of brain size in what is arguably the only other mammalian order that is as behaviorally complex as primates, viz., the cetaceans. Moreover, most of these studies have generally consisted of very small samples [Jerison, 1978; Wood and Evans, 1980; Ridgway and Brownson, 1984; Worthy and Hickie, 1986]. Other reports contain brain weight and body weight data but do not include a direct comparison of $E \mathrm{Q}$ values nor exclude data from specimens that are ill, gravid, emaciated, of unknown age, or otherwise less than optimal for developing a normative database for each species [Jansen and Jansen, 1969; Pilleri and Busnel, 1969; Pilleri and Gihr, 1970a; Kamiya and Yamasaki, 1974; Morgane and Jacobs, 1972].

There is, therefore, a relative dearth of information about normative levels of encephalization in cetaceans compared with other mammalian groups. Consequently, cetacea have been largely neglected in the formation of most major theories about mammalian brain evolution. Yet, obtaining data on brain size and its relation to behavior in cetaceans is critical because primate-cetacean comparisons present a unique opportunity to test the generality of hypothesized mechanisms about mammalian brain evolution and intelligence. Furthermore, primate-cetacean encephalization comparisons are particularly powerful because of the highly dissimilar ecological and evolutionary histories of the two groups. Specifically, anthropoid primates are best compared with one particular cetacean group, the odontocetes (toothed whales, dolphins, and porpoises), because these are the two suborders within their respective orders that are most comparable in body size and behavioral complexity. Therefore, this paper presents the following: (1) the first comprehensive compilation of normative brain weight and body weight data in odontocetes; (2) the first large database of calculated EQ values for 21 odontocetes species from all six families within the suborder; and, (3) the first direct quantitative comparison of EQ values in primates and cetaceans.

\section{Materials and Methods}

Normative data on body weight and length for each of the 21 odontocete species in this study were obtained from Ridgway [1972], Pirlot and Kamiya [1975], Bryden [1986], and Leatherwood and Reeves [1990]. Normative body weight and length data for the 60 anthropoid primate species in this study were obtained from Napier and Napier [1967], Laird [1969], and Tylinek and Berger [1985]. Odontocete and anthropoid specimens were included only if they possessed a body length and weight within the normal range of species-specific values for adults. Data from ill, emaciated, or gravid specimens were excluded.

One hundred and thirteen adult fresh brain weights and body weights from the literature, comprising 60 species from all seven anthropoid families, made up the anthropoid primate data set from which mean encephalization values for each of the species were calculated. A small subset of these 113 values are actually means of several individual data points. In the few cases of reported preserved brain weights, only those values that were corrected for the effect of fixation fluid on brain weights according to Stephan et al. [1970] were included. 
A subset of the odontocete data was taken from the literature for 75 individual adult specimens comprising all six odontocete families. Within this subset, data from all specimens represent fresh brain weights and body weights (with the one exception being the data on the Amazon river dolphin (Inia geoffrensis) from Best and da Silva [1989], which is based on cranial volume instead of brain weight). In addition to the 75 specimens, the odontocete data set incorporated a subset of 17 adult specimens with known body weights from the Marine Mammal collection at the National Museum of Natural History, The Smithsonian Institution, whose cranial volumes were directly measured by the author using a standard volumetric technique by which the cranium is filled with plastic beads [Radinsky, 1967]. Because the specific gravity of brain tissue is close to one, cranial volume yields reasonably accurate estimations of brain weight. All mean brain weight values determined by the present author incorporate cranial volumes measured by this method. Reliability data for cranial volume measurements are reported in the Results section. Therefore, in total, the odontocete data set consisted of brain weight (or cranial volume) and body weight data for a total of 92 individual adult specimens. The data set comprises 21 species from all six odontocete families from which mean EQ values for each of the species were calculated.

Encephalization Quotient (EQ) values for each odontocete and anthropoid species in the present sample were calculated from log mean brain weights (or cranial volumes in the case of the 17 odontocete specimens) and log mean body weights for each species. Two forms of EQ were calculated. First, the equation $\mathrm{EQ}=$ brain weight/0.12 (body weight) ${ }^{0.67}$ from Jerison [1973] was used to derive $\mathrm{EQ}$ values for each species. Hereafter this relation will be referred to as EQ 0.67. The present sample of EQ 0.67 values may be interpreted as loosely expressing how encephalized each species is with reference to a general mammalian sample; these values are widely used for such comparisons in the literature.

Second, an equation was empirically derived from the regression of log brain weight on log body weight for the present anthropoid-odontocete data set. The following resulting equation (referred to as EQ 0.72 ), $\mathrm{EQ}=$ brain weight/0.17 (body weight) ${ }^{0.72}$, was then used to calculate $\mathrm{EQ}$ values for each species in the sample. Therefore, EQ 0.72 may be interpreted as a given species' level of encephalization as a member of the present anthropoid-odontocete sample.

To reiterate, two sets of EQ values were calculated for each anthropoid and odontocete species in the present sample: EQ 0.67 and EQ 0.72 . Also, separate values for males and females were calculated in order to determine if there are sex differences in encephalization both within and between the two samples.

\section{Results}

In order to evaluate the reliability of the cranial volume measures of the 17 odontocete specimens included in the present data set, measurements were repeated 1-3 days after the initial measurement for a randomly chosen nine of the 17 crania. The difference between the first and second measure was converted into a percent difference score for each specimen. The mean percent difference score was $1.34 \%$. Therefore, the reliability of the present sample of cranial volume measurements was well within the $2 \%$ error typically found in the primate literature.

Table 1 displays the mean brain weight, mean body weight, and sources for the 60 anthropoid primate species in the present sample, along with the number of individual specimens (n) upon which each species value is based and the sources of those values. Values are presented for adults and combined sexes. 
Table 1. Mean brain weight, mean body weight, and mean brain weight/body weight ratio for 60 anthropoid primate species (adults, combined sexes)

\begin{tabular}{|c|c|c|c|c|c|c|c|c|c|}
\hline Species & $\mathrm{n}$ & $\begin{array}{c}\text { Brain } \\
\text { weight(g) }\end{array}$ & $\begin{array}{c}\text { Body } \\
\text { weight(g) }\end{array}$ & Source & Species & $\mathrm{n}$ & $\begin{array}{c}\text { Brain } \\
\text { weight(g) }\end{array}$ & $\begin{array}{c}\text { Body } \\
\text { weight(g) }\end{array}$ & Source \\
\hline Callithrix jacchus & $8(7)$ & 007.7 & 233.0 & $\mathrm{c}, \mathrm{h}, \mathrm{i}$ & Papio anubis & 2 & 211.5 & 30000.0 & $h, i$ \\
\hline Callithrix geoffroyi & $8(8)$ & 019.9 & 793.0 & $d$ & Papio papio & 1 & 193.0 & 21800.0 & a \\
\hline Cebuella pygmaea & 1 & 004.2 & 120.0 & $h, i$ & Papio ursinus & 1 & 181.0 & 24490.0 & a \\
\hline Saguinas midas & 2 & 010.4 & 345.0 & $a, i$ & Papio cynocephalus & 2 & 194.0 & 20865.0 & $a, d$ \\
\hline Saguinas oedipus & 4 & 009.7 & 383.0 & $\mathrm{~b}, \mathrm{~h}, \mathrm{i}$ & Papio hamadryas & 2 & 160.5 & 14010.0 & a, c \\
\hline Saguinas tamarin & 1 & 009.5 & 410.0 & $\mathrm{a}$ & Mandrillus sphinx & 1 & 179.0 & 32000.0 & a \\
\hline Callimico goeldi & 1 & 011.0 & 480.0 & $h, i$ & Presbytus entellus & 1 & 199.4 & 21319.0 & a \\
\hline Cebus albifrons & 1 & 071.0 & 3100.0 & $h, i$ & Presbytus cristatus & 1 & 081.7 & 16500.0 & a \\
\hline Cebus apella & 3 & 069.5 & 2327.0 & $a, b$ & Presbytus obscurus & 1 & 064.7 & 7030.0 & a \\
\hline Cebus capucinus & $23(22)$ & 72.7 & 3354.0 & $a, d$ & Cercopithecus mona & 1 & 069.3 & 5300.0 & a \\
\hline Aotus trivirgatus & 1 & 017.1 & 830.0 & $h, i$ & Cercopithecus ascanius & 2 & 069.3 & 3950.0 & $\mathrm{a}, \mathrm{h}, \mathrm{i}$ \\
\hline Callicebus moloch & 2 & 018.4 & 785.0 & $\mathrm{a}, \mathrm{h}, \mathrm{i}$ & Cercopithecus mitis & 3 & 074.4 & 6367.0 & $\mathrm{a}, \mathrm{d}, \mathrm{h}, \mathrm{i}$ \\
\hline Callicebus cupreus & 1 & 014.0 & 514.0 & a & Cercopithecus aethiops & 7 & 066.7 & 4324.0 & $a, b, d$ \\
\hline Saimiri sciureus & 4 & 024.2 & 648.0 & $a, b, h, i$ & Cercopithecus pygerythrus & 1 & 072.6 & 5670.0 & a \\
\hline Saimiri oerstedii & $86(85)$ & 024.2 & 753.0 & $d$ & Cercopithecus Ihoesti & 1 & 093.0 & 8500.0 & a \\
\hline Pithecia monachus & 1 & 035.0 & 1500.0 & $h, i$ & Cercopithecus hamlyni & 1 & 072.2 & 6000.0 & a \\
\hline Alouatta seniculus & 2 & 049.4 & 4990.0 & $\mathrm{a}, \mathrm{h}, \mathrm{i}$ & Miopithecus talapoin & 1 & 040.0 & 1200.0 & $h, i$ \\
\hline Alouatta palliata & $30(30)$ & 052.7 & 6896.0 & $d$ & Erythrocebus patas & 1 & 108.0 & 7800.0 & $h, i$ \\
\hline Alouatta villosa & 1 & 065.5 & 7824.0 & a & Colobus badius & $2(2)$ & 078.0 & 7000.0 & $h, i$ \\
\hline Ateles geoffroyi & $84(83)$ & 108.7 & 8082.0 & $\mathrm{~d}, \mathrm{~h}, \mathrm{i}$ & Pygathrix nemaeus & 1 & 077.0 & 7500.0 & $h, i$ \\
\hline Ateles belzebuth & 1 & 118.4 & 8890.0 & $\mathrm{a}$ & Nasalis larvatus & 1 & 097.0 & 14000.0 & $h, i$ \\
\hline Lagothrix lagothrica & 1 & 101.0 & 5200.0 & $h, i$ & Hylobates lar & $4(3)$ & 099.7 & 5664.0 & $\mathrm{c}, \mathrm{h}, \mathrm{i}$ \\
\hline Macaca mulatta & 4 & 093.8 & 6652.0 & $a, b, h, i$ & Hylobates pileatus & 1 & 103.0 & 5450.0 & c \\
\hline Macaca sinica & 1 & 084.0 & 8392.0 & a & Hylobates moloch & 1 & 097.4 & 6228.0 & $\mathrm{a}$ \\
\hline Macaca nemestrina & 1 & 122.0 & 8610.0 & $\mathrm{a}$ & Hylobates agilis & 1 & 087.5 & 7372.0 & $\mathrm{a}$ \\
\hline Macaca fascicularis & 3 & 070.8 & 5060.0 & $a, b$ & Symp syndactylus & $3(2)$ & 131.5 & 11117.0 & a, c \\
\hline Macaca arctoides & 2 & 100.7 & 7630.0 & $b$ & Pan troglodytes & 3 & 390.0 & 48893.0 & $\mathrm{~d}, \mathrm{~h}, \mathrm{i}$ \\
\hline Cercocebus albigena & 1 & 110.0 & 9200.0 & $h, i$ & Pongo pygmaeus & 6 & 351.7 & 63730.0 & $a, f$ \\
\hline Cercocebus torquatus & 1 & 140.0 & 8660.0 & a & Gorilla gorilla & 4 & 480.3 & 114654.0 & $a, g, h, i$ \\
\hline Cercocebus galeritus & 1 & 188.5 & 10700.0 & $\mathrm{a}$ & Homo sapiens & 1657(1656) & 1306.0 & 57333.0 & $e, h, i$ \\
\hline
\end{tabular}

Sources: a=Bauchot and Stephan [1969]; b=Bronson [1981]; c=von Bonin [1936]; d=Crile and Quiring [1940]; e=Gjukic [1955], cited

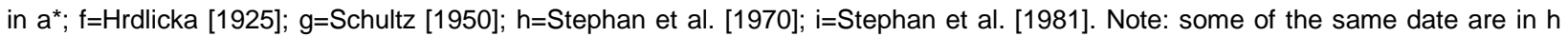
and i. $g=G r a m s ; n=n u m b e r$ of specimens on which brain and body weight are based; ()=subset of $n$ that are actually averaged values, otherwise $\mathrm{n}$ is made up of known individual specimens. 
Table 2 displays the mean brain weight, mean body weight, and sources for the 21 odontocete species in the present sample, along with the number of individual specimens (n) upon which each species value is based and the sources of those values. Values are presented for adults and combined sexes.

Table 2. Mean brain weight, mean body weight, and mean brain weight/body weight ratio for twenty-one Odontocete species (adults, combined sexes)

\begin{tabular}{|lcrrc|}
\hline Species & $\mathrm{n}$ & $\begin{array}{c}\text { Brain } \\
\text { weight(g) }\end{array}$ & $\begin{array}{c}\text { Body } \\
\text { weight(g) }\end{array}$ & Source \\
\hline Mesoplodon mirus & 2 & 2355.0 & 929500.0 & $\mathrm{~g}$ \\
Mesoplodon europaeus & 2 & 2149.0 & 732500.0 & $\mathrm{~g}$ \\
Mesoplodon densirostris & 3 & 1463.0 & 767000.0 & $\mathrm{~g}$ \\
Ziphius cavirostris & 1 & 2004.0 & 2273000.0 & $\mathrm{o}$ \\
Kogia breviceps & 3 & 1012.0 & 305000.0 & $\mathrm{~g}, \mathrm{o}$ \\
Kogia simus & 2 & 622.0 & 168500.0 & $\mathrm{~g}$ \\
Delphinapterus leucas & 1 & 2083.0 & 636000.0 & $\mathrm{o}$ \\
Monodon monoceros & 3 & 2997.0 & 1578330.0 & $\mathrm{~d}$ \\
Lipotes vexillifer & 1 & 510.0 & 82000.0 & $\mathrm{c}$ \\
Inia geoffrensis & 15 & 632.0 & 90830.0 & $\mathrm{a}, \mathrm{j}$ \\
Platanista gangetica & 4 & 295.0 & 59630.0 & $\mathrm{k}$ \\
Pontoporia blainvillei & 14 & 221.0 & 34890.0 & $\mathrm{e}, \mathrm{g}, \mathrm{l}$ \\
Phocoena phocoena & 1 & 500.0 & 61100.0 & $\mathrm{I}$ \\
Phocoenoides dalli & 11 & 866.0 & 86830.0 & $\mathrm{I}, \mathrm{q}$ \\
Tursiops truncatus & 20 & 1824.0 & 209530.0 & $\mathrm{~b}, \mathrm{f}, \mathrm{g}, \mathrm{h}, \mathrm{m}, \mathrm{n}, \mathrm{p}$ \\
Sotalia fluviatilis & 1 & 688.0 & 42240.0 & $\mathrm{~h}$ \\
Lagenorhynchus obliquidens & 4 & 1148.0 & 91050.0 & $\mathrm{~h}, \mathrm{l}, \mathrm{q}$ \\
Delphinus delphis & 6 & 815.0 & 60170.0 & $\mathrm{i}$ \\
Grampus griseus & 3 & 2387.0 & 328000.0 & $\mathrm{~g}, \mathrm{l}, \mathrm{o}$ \\
Globicephala melaena & 5 & 2893.0 & 943200.0 & $\mathrm{~b}, \mathrm{~g}, \mathrm{j}, \mathrm{I}$ \\
Orcinus orca & 2 & 5059.0 & 1955450.0 & $\mathrm{I}$ \\
\hline
\end{tabular}

Sources: a=Best and da Silva [1989]; b=von Bonin [1936]; c=Chen [1979]; d=Hay and Mansfield [1989]; e=Kamiya and Yamasaki [1974]; f=Kruger [1959]; g=Marino [1995]; h=Morgane and Jacobs [1972]; i=Pilleri and Busnel [1969]; j=Pilleri and Gihr [1968]; k=Pilleri and Gihr [1970a]; I=Pilleri and Gihr [1970b]; m=Ridgway [1990]; n=Ridgway and Brownson [1979]; o=Ridgway and

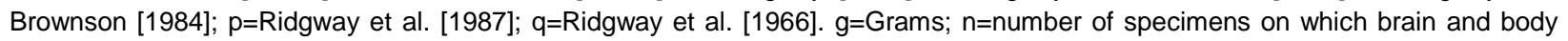
weights are based.

Figure 1 displays log brain weight regressed on log body weight for both the primate and odontocete samples. A least-squares regression of brain weight on body weight in the anthropoid sample (sexes combined) yielded a regression equation and correlation coefficient, brain weight $=0.182$ (body weight $^{0.70}$ and $r=0.962, \mathrm{p}<0.0001$, consistent with values previously obtained for similar anthropoid samples [Bronson, 1981; Eisenberg, 1981; Stephan et al., 1970, 1988; Pagel and Harvey, 1989]. There was also a significantly lower mean brain weight-body weight ratio in male anthropoids than in female anthropoids, $t=3.01, p<0.009$. Nevertheless, the slope of the relation between brain weight and body weight in male and female anthropoid primates was not different. A least-squares regression of brain weight on body weight for the odontocete sample (sexes combined) yielded the following regression 
equation and correlation coefficient: brain weight $=1.60$ (body weight) ${ }^{0.53}$ and $r=0.878, p<0.0001$. There were no differences in brain weight-body weight ratios between males and females in the odontocete sample.

Fig. 1. Log brain weight regressed on log body weight for both the primate and odontocete samples. $\mathbf{O}=$ Anthropoid primates; $\boldsymbol{\Lambda}=$ odontocetes.

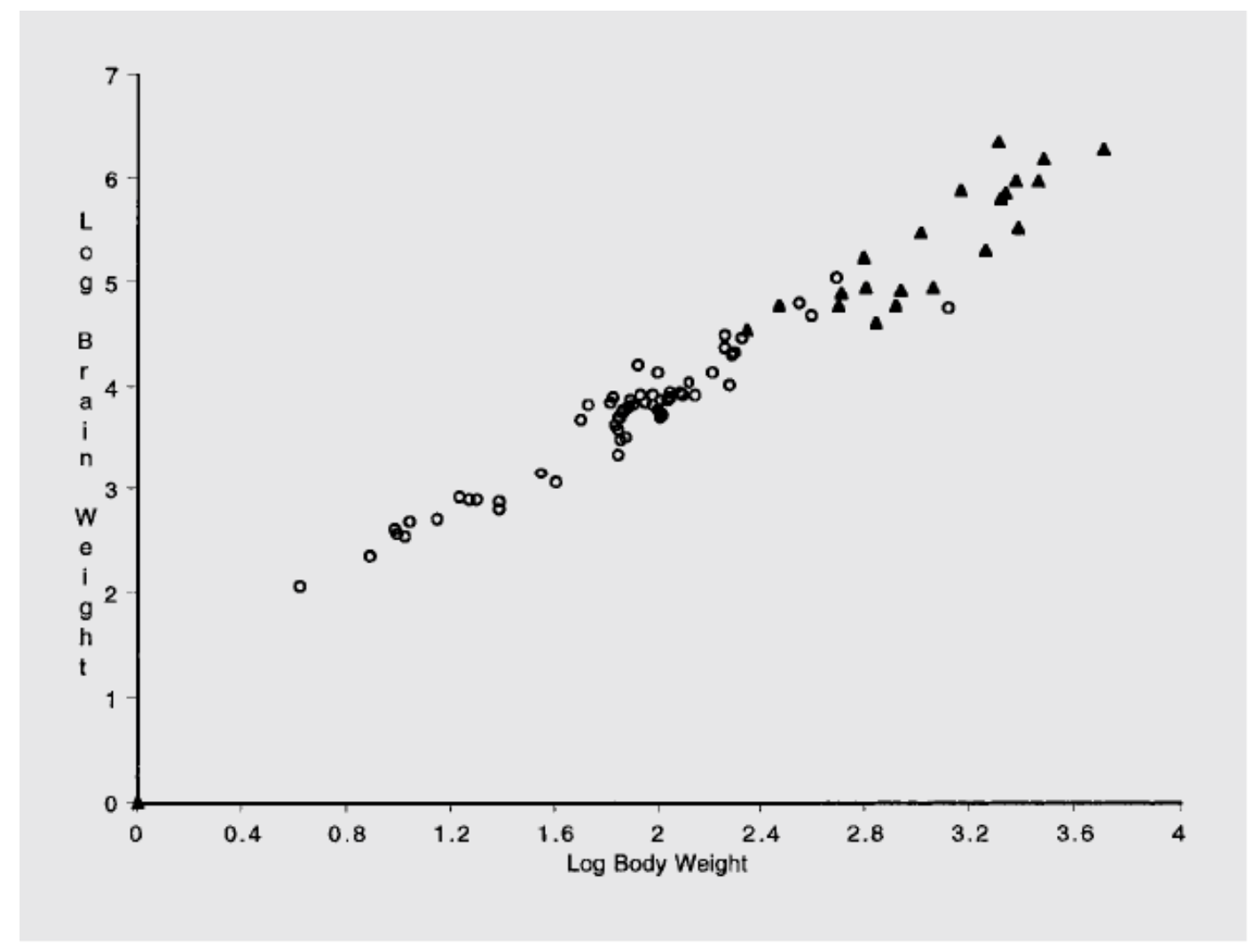

Figure 2 displays the mean EQ 0.67 values for each family (sexes combined) in the overall anthropoidodontocete sample. 
Fig. 2. Mean EQ 0.67 values for each family (sexes combined) in the overall anthropoid primate-odontocete sample. ATEL = Atelidae; CALL = Callitrichidae; $\mathrm{CEB}=$ Cebidae; $\mathrm{CERC}=$ Cercopithecidae; $\mathrm{DELPH}=\mathrm{Delphinidae} ; \mathrm{HOMO}=$ Homo sapiens; HYL = Hylobatidae; $\mathrm{MON}=$ Monodontidae; $\mathrm{PHOC}=$ Phocoenidae; $\mathrm{PHYS}=$ Physeteridae; $\mathrm{PLAT}=$ Platanistidae; PONG = Pongidae; ZIPH = Ziphiidae.

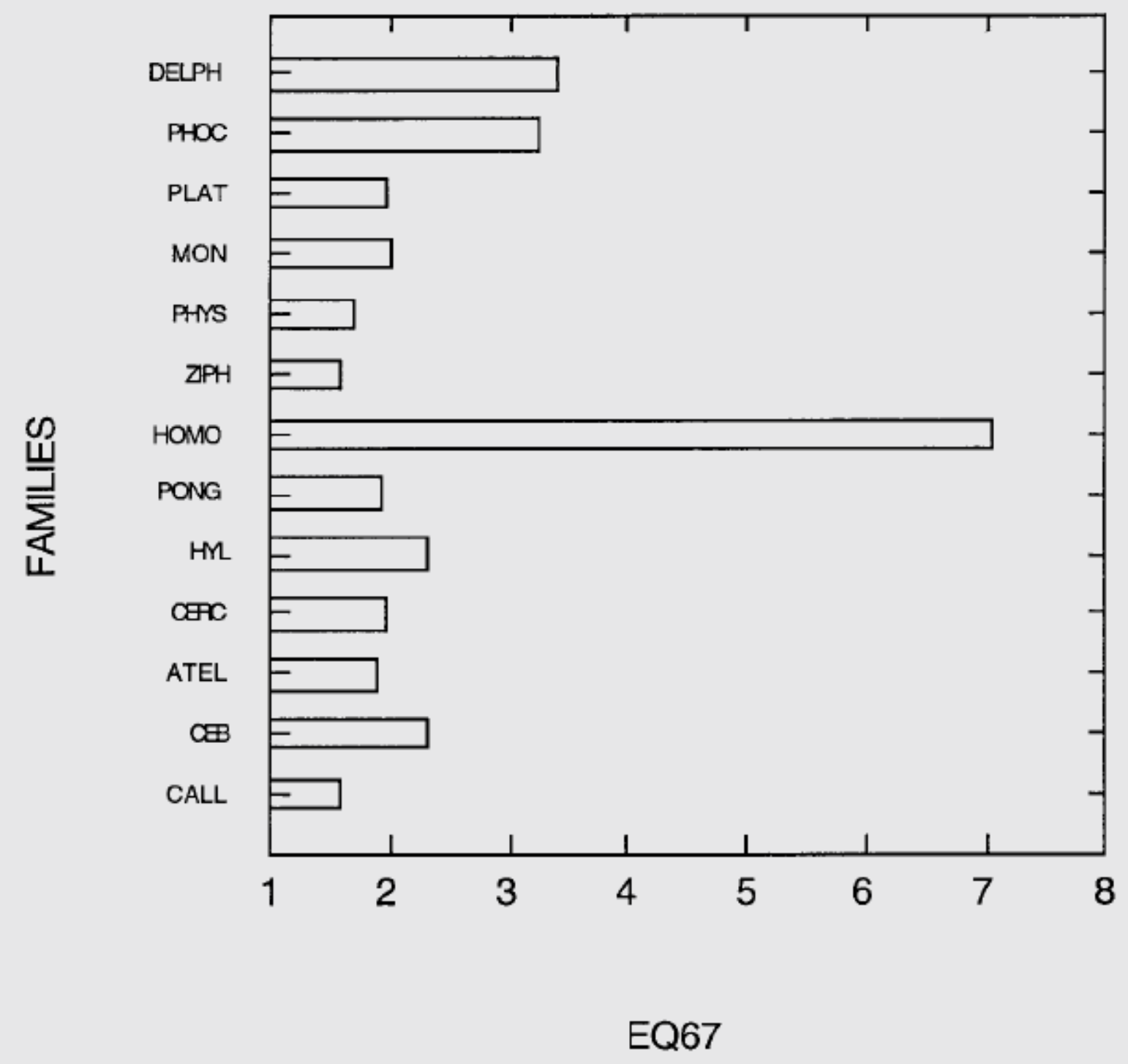

Figure 3 displays the mean EQ 0.72 values for each family (sexes combined) in the overall anthropoidodontocete sample. 
Fig. 3. Mean EQ 0.72 values for each family (sexes combined) in the overall anthropoid primate-odontocete sample (see fig. 2 for key to abbreviations).

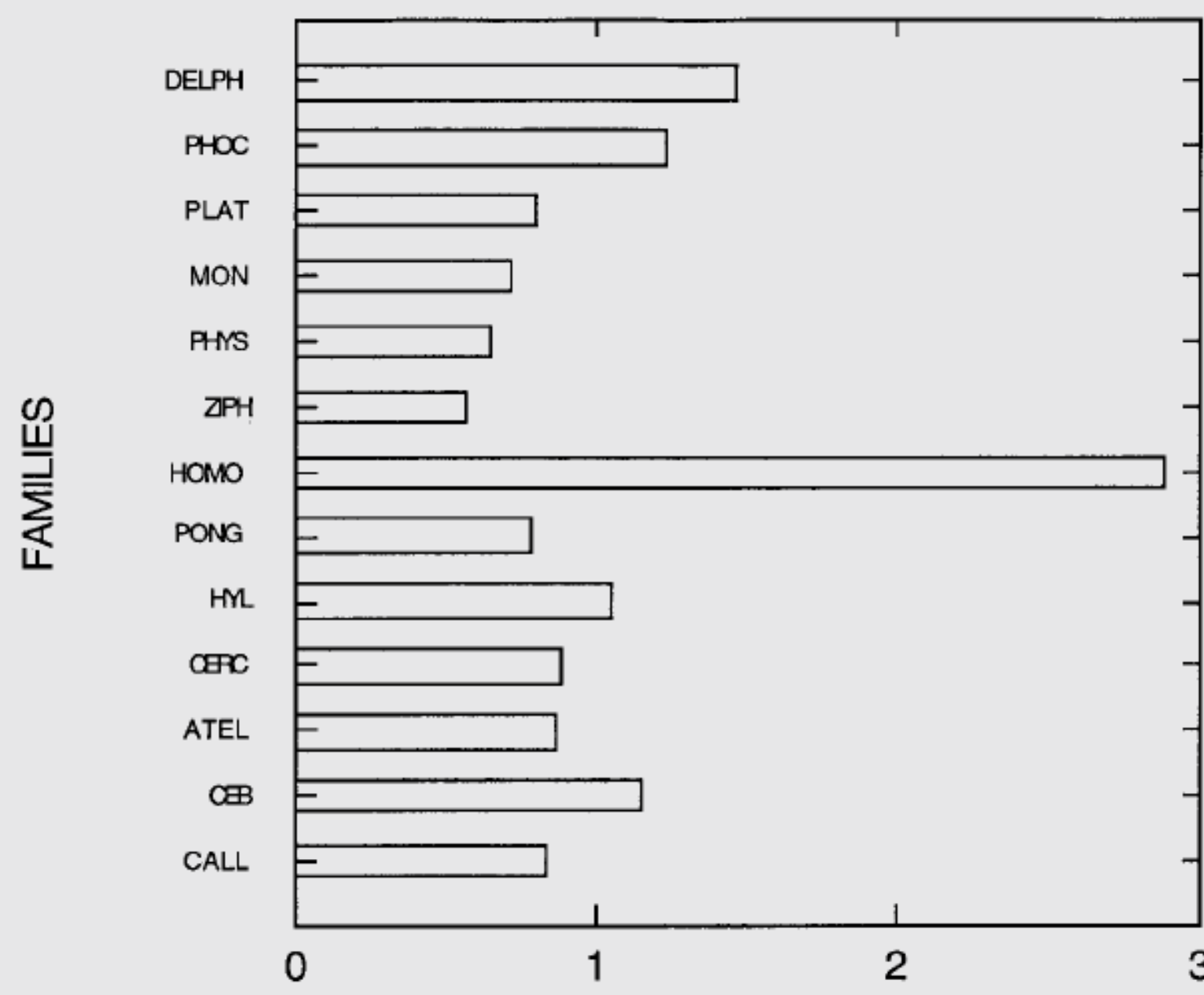

EQ72

There was no significant correlation between EQ 0.67 and body weight and EQ 0.72 and body weight in either the odontocete or anthropoid sample. Therefore, with some exceptions that will be discussed later, EQ values, in general, were able to be compared across species in the sample. As expected, the absolute values of EQ 0.67 and EQ 0.72 for each species were different because of the different reference groups each represents. Nevertheless, there was a strong positive correlation between each species' ranking across EQ 0.67 and EQ 0.72 values, $r=0.97, \mathrm{p}<0.001$.

All anthropoid and odontocete species (with the exception of Ziphius cavirostris) fell above the general mammalian regression line defined by EQ 0.67 . When EQ 0.72 was used, $28 \%$ of the total sample (26.7\% of the anthropoid sample and $33.3 \%$ of the odontocetes) ranked above average (i.e., above the regression line). The anthropoid subset was composed of Homo sapiens, five of eight species of 
Cebidae, three of four species of Hylobatidae, one of seven species of Atelidae, and six of 29 species of Cercopithecidae. The odontocete subset was composed of five of seven species of Delphinidae and both of the two species of Phocoenidae. Figure 4 displays the 23 species above the EQ 0.72 regression line in rank order.

Fig. 4. A rank order of the 23 species above the EQ 0.72 regression line. H.s. = Homo sapiens; S.f. = Sotalia fluviatilis; L.o. = Lagenorhynchus obliquidens; D.d. = Delphinus delphis; T.t. = Tursiops truncatus; C.a. = Cebus apella; G.g. = Grampus griseus; M.t. = Miopithecus talapoin; P.d. = Phocoenoides dalli; C.g. = Cercocebus galeritus; S.s. = Saimiri sciureus; C.al. = Cebus albifrons; L.I. = Lagothrix lagothrica; H.p. = Hylobates pileatus; C.c. = Cebus capucinus; S.o. = Saimiri oerstedii; C.t. = Cercocebus torquatus; H.I. = Hylobates lar; P.m. = Pithecia monachus; H.m. = Hylobates moloch; Ce.a. = Cercopithecus ascanius; P.p. = Phocoena phocoena; M.n. = Macaca nemestrina.

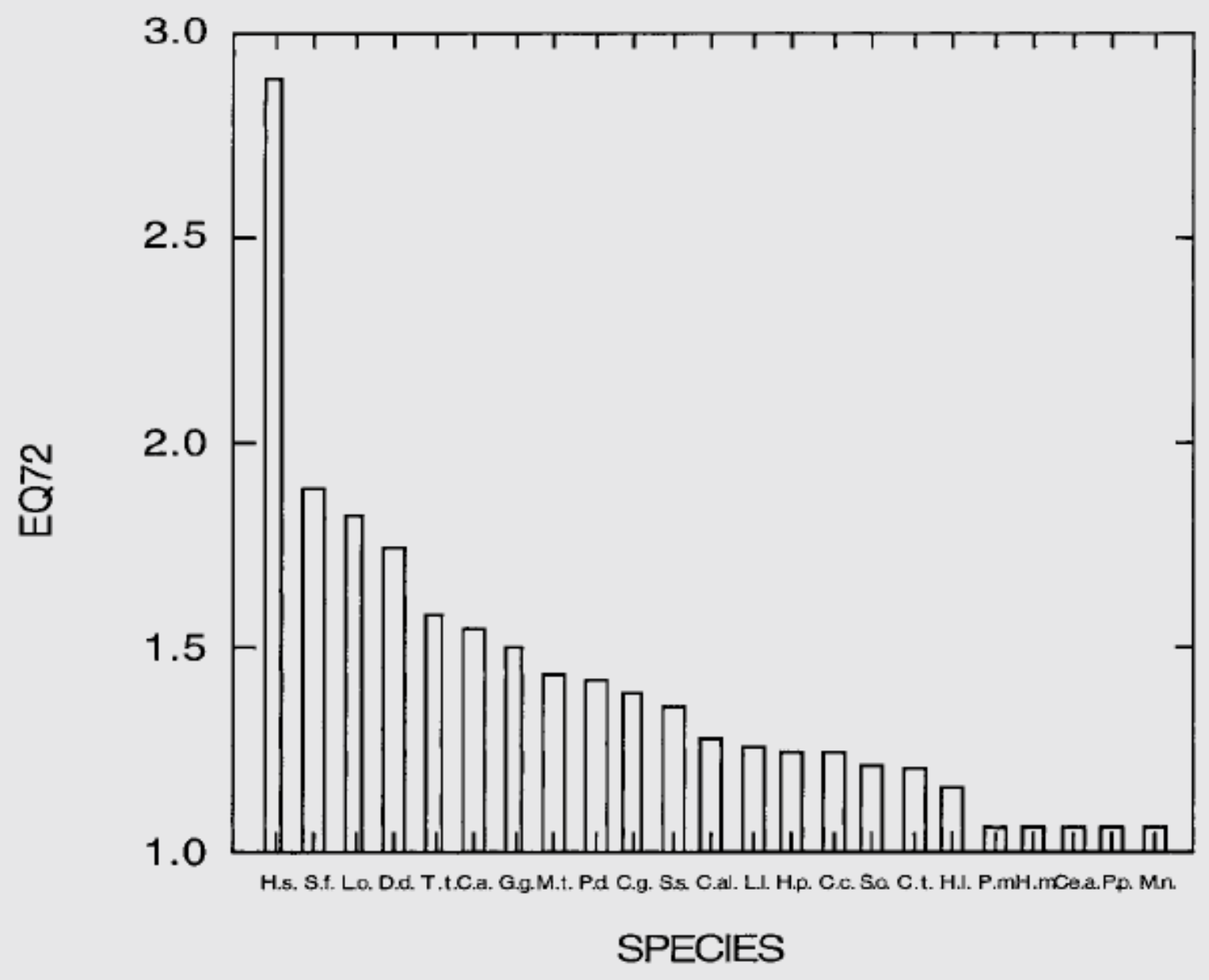

Although Homo sapiens ranked highest in EQ 0.67 and EQ 0.72 , four out of the five highest ranking species for both EQ 0.67 and EQ 0.72 were the same four species from the family Delphinidae: Sotalia fluviatilis, Lagenorhynchus obliquidens, Delphinus delphis, and Tursiops truncatus. Therefore, these 
delphinid species ranked above nonhuman anthropoid primates, including Pongidae, in both EQ 0.67 and EQ 0.72 .

From these results, three broad categories of encephalization may be defined. Because of the stability of the top five rankings for each species across EQ 0.67 and EQ 0.72 , the first category is composed of the above: $H$. sapiens, S. fluviatilis, L. obliquidens, D. delphis, and $T$. truncatus. The second category (which consists of most of the Cebidae, Hylobatidae, and Delphinidae and all of the Phocoenidae) is defined as the next set of eighteen species that fall above the EQ 0.72 regression line. The third category, which falls at or below the EQ 0.72 regression line, is composed of the remaining mixture of mostly Cercopithecidae, Pongidae, Callitrichidae, Atelidae, Monodontidae, Platanistidae, Physeteridae, and Ziphiidae.

\section{Discussion}

The results of the present study revealed that the slope of 0.70 relating brain weight to body weight in the anthropoid sample is substantially higher than that of 0.53 for the odontocete group. This shows that brain weight does not scale to body weight in exactly the same manner in primates and odontocetes. This pattern may be due to several related factors. First, many of the very large odontocetes are outside the weight range of the heaviest primates. These odontocete species' brain weight-body weight ratios (and EQ values), therefore, may be affected by the lack of comparison points in that body size range. Second, body size increases in cetaceans in general are not subject to the same gravitional restrictions as those on terrestrial mammals. Therefore, because of 'aquatic weightlessness', cetaceans may be able to obtain much larger body sizes than terrestrial animals without a similar increase in neural tissue. This has been previously suggested by Worthy and Hickie [1986]. Third, the proportion of body weight accounted for by subcutaneous fat, or blubber, may be much higher in cetaceans than in primates. Since blubber is not innervated this would present another way in which brain weight and body weight can be uncoupled in cetaceans. It is not unreasonable to argue that body weight in cetaceans may be accounted for by proportionally more blubber than body weight in primates. There is currently an inadequate amount of data to confidently quantify the proportion of body weight accounted for by blubber in most odontocete species. However, this factor will eventually become one that will need to be quantified and taken into account in order to obtain a better understanding of encephalization in cetaceans. Finally, it may be preliminary suggested that, since fewer gravitional constraints and more blubber may inflate body weight measures in cetaceans in relation to the size of the brain, encephalization levels in many cetacean species are currently being underestimated.

The results of the present study also revealed that the slope of the regression line relating brain size to body size is the same for both sexes in both the anthropoid primate and odontocete samples. However, one difference between the groups is that in anthropoid primates, mean female brain weight/body weight values are significantly greater than those of males. This is due to the fact that there are a number of primate species (especially Pongo pygmaeus and Gorilla gorilla) that exhibit substantial body size sexual dimorphisms that affect relative brain size. Given what is known about orangutan and gorilla behavior, sexual dimorphisms in relative brain size (and, consequently, EQ) within these species are due to secondary increases in body size in males and not to differences in intelligence or encephalization per se. In contrast there is practically no sexual dimorphism in body size among odontocetes. When it does exist, about the same number of species exhibit female $>$ male body size dimorphism as do those that exhibit male $>$ female dimorphism.

In both the anthropoid primate and odontocete samples EQ 0.67 absolute values were lower than EQ 0.72 values because the reference groups for each EQ measure are different. The EQ 0.67 values reflect 
how encephalized each of the odontocete and anthropoid species are compared with a general mammalian regression curve from the literature [Jerison, 1973]. All but one species in the sample, Ziphius cavirostris, fell above the regression line for mammals. Even the value for $Z$. cavirostris is not far below the mammalian regression line. The EQ 0.72 values are, on an absolute scale, lower than EQ 0.67 values because, whereas almost all anthropoid primates and odontocetes are highly encephalized when mammals are used as the reference group, many inevitably fall below the reference line when fellow anthropoid primates and odontocetes are used as the reference group. Furthermore, when compared with each other, a greater proportion of odontocetes (33.3\%) are above average in EQ than are anthropoid primates (26.6\%). Finally, regardless of the difference in absolute value between EQ 0.67 and EQ 0.72 , the rankings of species in both groups using the two measures was strongly positively correlated.

One of the more striking, and perhaps unexpected, results of the present study is that a number of odontocete species in the family Delphinidae possess EQ levels that consistently rank above that of any other species, including the three Pongidae species. The odontocetes S. fluviatilis, L. obliquidens, $D$. delphis, and $T$. truncatus possess significantly higher EQ levels than any other odontocetes in the sample and all anthropoid primates except $H$. sapiens. These findings reveal than the gap between human and nonhuman levels of encephalization (and, in a general way, intelligence) is substantially narrowed by a nonprimate group that is more similar to humans in terms of level of encephalization than is our closest living relative, Pan, thus demonstrating that similar levels of encephalization can emerge in very different phylogenetic lineages. Furthermore, these findings are potentially more striking within the context of the possibility that encephalization level may be underestimated in some or all cetaceans.

One of the most important ways the above findings can be utilized is to provide a comparative model of the relative importance of brain size over brain organization in the evolution of mammalian intelligence. Although closest to humans in measures of size, cetacean brain organization (i.e., morphology and cytoarchitecture) is markedly different than that of any primate, including humans [Morgane and Jacobs, 1972; Morgane et al., 1980; Glezer et al., 1988]. Notably, those features considered hallmarks of primate cytoarchitectural trends, such as granularization and a distinct Layer 4, are absent in cetacean brains. Cetacean brains, on the other hand, exhibit an unusual pattern of 'cortical adjacency' in the topography of functional projection regions and also possess a paralimbic region, both features of which are absent in primate brains. Therefore, the confluence of these striking differences in organization and similarity in encephalization level between many primate and cetacean species provides an opportunity to test specific hypotheses about the generalizability of mammalian brainbehavior relations. As more information on cetacean life history variables [Marino, 1997] becomes available, these hypotheses will, for the first time, allow us to address the issue of whether there are alternative evolutionary paths to similar behavioral ecological niches in the two most highly encephalized existing organisms.

\section{Acknowledgements}

The author wishes to thank James Mead and Charles Potter of the Marine Mammal Program, National Museum of Natural History, The Smithsonian Institution, for the use of their cetacean collection. The author also thanks Budd Puckett for his technical assistance in modifying the materials used to measure cranial volumes and Scott Lilienfeld, who offered valuable editorial assistance. 


\section{References}

Armstrong, E. (1982) A look at relative brain size in mammals. Neurosci. Lett., 34: 101-104.

Armstrong, E. (1983) Relative brain size and metabolism in mammals. Science, 220: 1302-1304.

Armstrong, E. (1985) Allometric considerations of the adult mammalian brain with special emphasis on primates. In Size and Scaling in Primate Biology (ed. by W.J. Jungers), Plenum Press, New York, London, pp. 115-146.

Bauchot, R., and H. Stephan (1969) Encéphalisation et niveau évolutif chez les simiens. Mammalia, 33: 235-275.

Best, R.C., and V.M. da Silva (1989) Amazon River dolphin, Boto Inia geoffrensis (de Blainville, 1817). In Handbook of Marine Mammals, Vol. 4: River Dolphins and the Larger Toothed Whales (ed. by S.H. Ridgway and R. Harrison), Academic Press, New York, pp. 1-24.

Bronson, R.T. (1981) Brain weight-body weight relationships in twelve pieces of nonhuman primates. Am. J. Phys. Anthropol., 56: 77-81.

Bryden, M.M. (1986) Age and growth. In Research on Dolphins (ed. by M.M. Bryden and R. Harrison), Clarendon Press, Oxford, pp. 211-224.

Chen, I. (1979) On the cerebral anatomy of Chinese river dolphin, Lipotes vexillifer. Acta Hydrobiol. Sinica, 6: 366-372.

Crile, G., and D.P. Quiring (1940) A record of the body weight and certain organ and gland weights of 3,690 animals. Ohio J. Sci., XL(5): 219-389.

Eisenberg, J.F., and D.E. Wilson (1978) Relative brain size and feeding strategies in the Chiroptera. Evolution, 32: 740-751.

Eisenberg, J.F., and D.E. Wilson (1981) Relative brain size and demographic strategies in didelphid marsupials. Am. Nat., 118: 1-15.

Gjukic, M. (1995) Ein Beitrag zum Problem der Korrelation zwischen Hirngewicht und Körpergewicht. Z. Morphol. Anthropol., 47: 43-57.

Glezer, I., M.S. Jacobs, and P.J. Morgane (1988) Implications of the 'initial brain' concept for brain evolution in Cetacea. Behav. Brain Sci., 11: 75-116.

Harvey, P., and J.R. Krebs (1990) Comparing brains. Science, 249: 140-146.

Hay, K., and A. Mansfield (1989) Narwahl (Monodon monoceros Linnaeus, 1758). In Handbook of marine mammals, Vol. 4: River Dolphins and the Larger Toothed Whales (ed. by S. Ridgway and R. Harrison), Academic Press, New York, pp. 145-176. 
Hofman, M.A. (1982) Encephalization in mammals in relation to the size of the cerebral cortex. Brain Behav. Evol., 20: 84-96.

Hofman, M.A. (1983) Energy metabolism, brain size and longevity in mammals. Q. Rev. Biol., 58: 496512.

Holloway, R.L. (1980) Within-species brain-body weight variability: a re-examination of the Danish data and other primate species. Am. J. Phys. Anthropol., 53: 109-121.

Hrdlicka, A. (1925) Weight of the brain and of the internal organs in American monkeys. Am. J. Phys. Anthropol., 8(2): 201-211.

Jansen, J., and J.K. Jansen (1969) The nervous system of Cetacea. In Biology of Marine Mammals (ed. by H. Anderson), Academic Press, New York, pp. 175-252.

Jerison, H.J. (1955) Brain to body ratios and the evolution of intelligence. Science, 121: 447-449.

Jerison, H.J. (1963) Interpreting the evolution of the brain. Human Biol., 35: 263-291.

Jerison, H.J. (1973) Evolution of the Brain and Intelligence. Academic Press, New York, N.Y.

Jerison, H.J. (1978) Brain and intelligence in whales. In Whales and Whaling: Vol. 2 (ed. By S. Frost), C.J. Thompson, Australian Commonwealth Government Printer, Canberra, pp. 159-197.

Kamiya, T., and F. Yamasaki (1974) Organ weights of Pontoporia vlainvillei and Platanista gangetica (Plastanistidae). Scientific Reports of the Whale Research Institute, 32: 105-126.

Kruger, L. (1959) The thalamus of the dolphin Tursiops truncatus and comparison with other mammals. J. Comp. Neurol., 3: 133-194.

Laird, A. (1969) The dynamics of growth. Res. Dev., 20: 28-31.

Leatherwood, S., and R.R. Reeves (1990) The Bottlenose Dolphin. Academic Press, London.

Mace, G.M., P.H. Harvey, and T.H. Clutton-Brock (1980) Is brain size and ecological variable? Trends Neurosci., 3: 193-196.

Marino, L. (1995) Brain-behavior relationships in cetaceans and primates: implications for the evolution of complex intelligence. Ph.D. dissertation, State University of New York, University at Albany, Albany, New York.

Marino, L. (1997) The relationship between gestation length, encephalization, and body weight in odontocetes. Marine Mammal Sci., 13(1): 133-138.

Martin, R. (1981) Relative brain size and basal metabolic rate in terrestrial vertebrates. Nature, 293: 6067. 
McNab, B.K., and J.F. Eisenberg (1989) Brain size and its relation to the rate of metabolism in mammals. Am. Nat., 133(2): 157-167.

Morgane, P.J., and M.S. Jacobs (1972) Comparative anatomy of the cetacean nervous system. In Functional Anatomy of Marine Mammals, Vol. 1 (ed. by R.J. Harrison), Academic Press, London, pp. 118-244.

Morgane, P.J., M.S. Jacobs, and W.L. McFarland (1980) The anatomy of the brain of the bottlenose dolphin (Tursiops truncatus). Surface configurations of telencephalon of the bottlenose dolphin with comparative anatomical observations in four other cetacean species. Brain Res. Bull., 5(3): 1-108.

Pagel, M., and P. Harvey (1989) Taxonomic differences in the scaling of brain on body weight among mammals. Science, 244: 1589-1593.

Napier, J.R., and P.H. Napier (1967) A Handbook of Living Primates. Academic Press, London.

Passingham, R.E. (1975) The brain and intelligence. Brain Behav. Evol., 11: 1-15.

Pilleri, G., and R. Busnel (1969) Brain/body weight ratios in Delphinidae. Acta Anat., 51: 241-258.

Pilleri, G., and M. Gihr (1968) On the brain of the Amazon dolphin Inia geoffrensis de Blainville, 1817 (Cetacea Susuidae). Experientia, 24: 932-934.

Pilleri, G., and M. Gihr (1970a) The central nervous system of the Mysticete and Odontocete whales. Invest. Cetacea, 2: 87-135.

Pilleri, G., and M. Gihr (1970b) Brain-body weight ratio of Platanista gangetica. Invest. Cetacea, 2: 79-82.

Pirlot, P., and T. Kamiya (1975) Comparison of ontogenetic brain growth in marine and coastal dolphins. Growth, 39: 507-525.

Radinsky, L. (1967) Relative brain size: a new measure. Science, 155: 836-837.

Ridgway, S.H. (1972) Mammals of the Sea: Biology and Medicine. Thomas, Springfield.

Ridgway, S.H. (1990) The central nervous system of the bottlenose dolphin. In The Bottlenose Dolphin (ed. by S. Leatherwood and R.R. Reeves), Academic Press, San Diego, California, pp. 69-100.

Ridgway, S.H., and R.H. Brownson (1979) Brain size and symmetry in three dolphin genera. Anat. Rec., 193: 664.

Ridgway, S.H., and R.H. Brownson (1984) Relative brain sizes and cortical surface areas in odontocetes. Acta Zool. Fennica, 172: 149-152.

Ridgway, S.H., L.S. Demski, T.H. Bullock, and M. Schwanzel-Fukuda (1987) The terminal nerve in odontocete cetaceans. Ann. New York Acad. Sci., 519: 201-212. 
Ridgway, S.H., N. Flanigan, and J. McCormick (1966) Brain-spinal cord ratios in porpoises: possible correlations with intelligence and ecology. Psychonomic Sci., 6(11): 491-492.

Schultz, A.H. (1950) Morphological observations on gorillas. In The Anatomy of the Gorilla (ed. by W.K. Gregory), Columbia University Press, New York, pp. 228-253.

Stephan, H., G. Baron, and H. Frahm (1988) Comparative size of brains and brain components. In Comparative Primate Biology, Vol. 4: Neurosciences (ed. by H. Steklis and J. Erwin), Alan R. Liss, New York, pp. 1-38.

Stephan, H., R. Bauchot, and O. Andy (1970) Data on size of the brain and of various brain parts in insectivores and primates. In The Primate Brain: Advances in Primatology, Vol. 1 (ed. By C.R. Noback and W. Montagna), Appleton-Century-Crofts, New York, pp. 289-298.

Stephan, H., H. Frahm, and G. Baron (1981) New and revised data on volume of brain structures in insectivores and primates. Folia Primatol., 35: 1-29.

Tylinek, E., and G. Berger (1985) Monkeys and Apes. Arco Publishing, Inc., New York.

von Bonin, G. (1936) Brain-weight and bodyweight of mammals. J. Gen. Psychol., 16: 379-389.

Wood, F.G., and W.E. Evans (1980) Adaptiveness and ecology of echolocation in toothed whales. In Animal Sonar Systems (ed. by R. Busnel and J. Fish), Plenum Press, New York, pp. 381-426.

Worthy, G.A., and J.P. Hickie (1986) Relative brain size in marine mammals. Am. Nat., 128: 445-459. 